\title{
EDITORIAL
}

\section{On being relationship-centred}

In my previous editorial, ${ }^{1}$ I mentioned the key ethos of our discipline, relationshipcentredness, which is a natural extension of our aspiration of focusing on the person behind the illness, by practising personcentred care within the context of the extended healthcare team. ${ }^{2}$ This aspiration is shared around the globe in the wider family medicine (FM) community. The different interpretations around the globe of what is meant by "general practice" and "family medicine" were discussed in one of the Besrour Centre's papers, which grappled with the challenge of finding a global definition of FM. ${ }^{3}$ The authors concluded that, universally, the discipline remained responsive to local health needs, despite being practised in various forms across the globe. To remain locally relevant, the discipline and its practitioners' unifying role (and identity) should remain grounded in relationships of care (with patients, colleagues and the community).

This reminded me again of how everything we do on a daily basis is centred on our ability to form, strengthen and sustain such relationships of care (or caring relationships), namely with our patients, our colleagues, our managers, our teams and our students, as well as our family and support structures. We exert our influence through others in the healthcare team, as our numbers as family physicians are low (both within the local team and on a national scale); this makes us dependent on these relationships in order to achieve what we are striving towards: enhancing the quality of care, role modelling the principles of our discipline, and strengthening the local healthcare system.

The family physician is tasked to help strengthen the district health services through leadership in all his/her roles as a clinician, consultant, capacity-builder, clinical trainer and champion of community-orientated primary care. In order to deliver on these expectations, registrars should be prepared during their postgraduate training. A national process reached consensus and outlined the key conceptual principles and competencies required for leadership and governance. ${ }^{4}$ These principles and competencies also echo those envisaged for the primary care doctor in the national postgraduate diploma in FM, aimed at re-orientating and upskilling the existing pool of primary care doctors working in both public and private sectors, in order to meet the challenges of the re-engineered primary healthcare system. ${ }^{5}$ The 'I-we-it' model of leadership serves as a central conceptual model of developing leadership ability. ${ }^{4}$
The 'I' refers to self-care, self-awareness and self-management, which influences our ability to reach out, form relationships and networks (the collective 'we'). The next important domain is the 'it', which focuses on knowing the context of the health system within which one is being a leader. During interviews exploring the influence of family physicians, district managers mentioned their expectation that family physicians will help the healthcare system to improve, expand and develop. ${ }^{6}$ However, family physicians who were seen to be 'at the mercy of the system' were those lacking leadership skills and not able to integrate themselves into the clinical team and context. The family physician's ability to influence the health service through their team depends on their capability for leadership, as well as obtaining support for their leadership across all their roles. Increasingly, our ability to build relationships should be used to help bridge the perceived divides between the private and public health sectors, as well as the health and education systems. Consequently, the ability to exert our influence through relationship-oriented leadership should not only be a core focus of our postgraduate training programmes, but should also feature strongly in the ongoing development and reflective practice of qualified family physicians and primary care practitioners.

During the recent WONCA Africa conference in Kampala, the WHO Africa regional representative, Dr Tumusiime Prosper, challenged us with a number of key questions regarding realising family physician-containing teams to achieve highquality PHC in the African region (see online report). ${ }^{7}$ Some of the answers may lie in our desire to become 'FM champions', as described by Professor Amanda Howe in her keynote: those who are able to help develop our discipline by being living examples in practice, contributing to the research base by documenting our progress and striving towards enhancing the quality of our care, engaging with managers and policy makers through advocacy and leadership, and being role models to our junior colleagues and students (the next generation of health workers). Our changing context and team dynamics will require us to demonstrate continual growth as leaders able to adapt to these changes by building on our relationships.

I would like to end by encouraging Academy members to use the South African Family Practice journal and the annual National Family Practitioners' Conference as suitable platforms to continue this conversation.

\section{Best wishes}

\section{Klaus B von Pressentin}

Editor-in-Chief

Twitter:@klausvon; @SAFPjournal 


\section{References:}

1. Von Pressentin KB. Growing the discipline of family medicine as a counterculture. South African Family Practice. 2019;61(2):5-6.

2. Nundy S, Oswald J. Relationship-centered care: A new paradigm for population health management. Healthcare. 2014;2(4):216-9).

3. Ponka D. The Besrour Papers: Seeking evidence for family medicine. African Journal Of Primary Health Care and Family Medicine. 2017;9(1):1-2.

4. Mash R, Blitz J, Malan Z, Von Pressentin K. Leadership and governance: learning outcomes and competencies required of the family physician in the district health system. South African Family Practice. 2016;58(6):232-5.
5. Mash R, Malan Z, Von Pressentin K, Blitz J. Strengthening primary health care through primary care doctors: the design of a new national Postgraduate Diploma in Family Medicine. South African Family Practice. 2015;58(1):32-6.

6. Von Pressentin KB, Mash RJ, Baldwin-Ragaven L, Botha RP, Govender I, Steinberg WJ. The bird's-eye perspective: how do district health managers experience the impact of family physicians within the South African district health system? A qualitative study. South African Family Practice. 2018;60(1):13-20.

7. Von Pressentin KB. Montegut scholar report on WONCA Africa conference. WONCA Global Family Doctor homepage; 2019. Available from: https://www.globalfamilydoctor.com/News/KlausvonPressentinMontegut.aspx [Accessed 23 July 2019]. 